\title{
Asansör Kabin Kılavuz Ray Konsol Tasarımlarının Deprem Yükü Altında Analizi ve Karşılaştırılması
}

\author{
Abdül Melik Sancak ${ }^{1 *}$, Adem Candaş², C. Erdem İmrak ${ }^{3}$ \\ 1* İstanbul Teknik Üniversitesi, Makina Fakültesi, İstanbul, Türkiye, (ORCID: 0000-0003-4004-5468), $\underline{\text { sancak17@itu.edu.tr }}$ \\ 2 İstanbul Teknik Üniversitesi, Makina Fakültesi, İstanbul, Türkiye (ORCID: 0000-0002-9951-9122), candas@itu.edu.tr \\ 3 İstanbul Teknik Üniversitesi, Makina Fakültesi, İstanbul, Türkiye (ORCID: 0000-0003-4428-0158), imrak@itu.edu.tr
}

(2nd International Conference on Access to Recent Advances in Engineering and Digitalization (ARACONF)-10-12 March 2021)

(DOI: 10.31590/ejosat.901663)

ATIF/REFERENCE: Sancak, A.M., Candaş, A. \& İmrak, C.E. (2021). Asansör Kabin Kılavuz Ray Konsol Tasarımlarının Deprem Yükü Altında Analizi ve Karşılaştırılması. Avrupa Bilim ve Teknoloji Dergisi, (24), 60-66.

$\ddot{\mathbf{O z}}$

Asansör sistemlerinin deprem gibi acil durumlarda kullanılabilir olması için kritik önemdeki aksamları ani ve aşırı zorlanmalara karşı dayanıklı olmalıdır. Sismik yükler gibi ani zorlanmalar, normal koşullar altında çalışmak için tasarlanmış asansör elemanlarını beklenmedik şekilde etkileyebilir. Kabin ve karşı ağırlığın kuyu içindeki hareketini sınırlayan kılavuz rayların asansör boşluğu boyunca sabitlenmesini sağlayan konsolların bu bağlamda incelenmesi oldukça önemlidir. Bu çalışmada, asansöre etki eden sismik yükler hesaplanmış ve elde edilen sonuçlar kullanılarak iki farklı konsol tasarımı sonlu elemanlar metodu ile analiz edilmiştir. Geliştirilen destekli konsol tasarımı, yaygın kullanımda olan geleneksel model ile gerilme ve şekil değiştirme açısından karşılaştırılmış ve değerlendirilmiştir.

\section{Analysis and Comparison of Elevator Cabin Guide Rail Bracket Designs Under Earthquake Load}

\begin{abstract}
Components of an elevator system are required to be strength in case of emergencies such as earthquakes causing instantaneous and unexpected loadings. Sudden stresses, such as seismic loads, can unexpectedly affect elevator members designed to operate under normal conditions. Therefore, it is essential to examine brackets that support rails along the elevator shaft, limiting the movement of cabin and counterweight in the shaft. In this study, seismic loads affecting an elevator were calculated and two different bracket designs were analysed using finite element method. The supported bracket design was compared to classical design in terms of stress and deformation values.
\end{abstract}

Keywords: Elevator, Seismic Loads, Earthquake, Elevator Bracket, Elevator Guide Rail.

* Sorumlu Yazar: sancak17@itu.edu.tr 


\section{Giriş}

Deprem gibi doğal afet durumlarında asansör sistemlerinin faal durumda kalması büyük önem arz etmektedir. Özellikle yüksek katlı binalarda, hastane ve okul gibi kamu binalarında asansörlerin deprem sirasında kullanıcı için tehlike oluşturmaması gerekir. Uzun süren mahsur kalma durumları veya sistemin bütüncül hasara uğraması kullanıcı açısından hayati risk oluşturabilir. $\mathrm{Bu}$ nedenle, depreme dayanıklı binalar inşa ederken asansör sistemleri de depreme uygun tasarlanmalıdır. Deprem sirasında en kritik olan yapısal elemanlardan biri, karşı ağırlık ve kabin raylarını asansör kuyusunun duvarlarına bağlayan ve rayların düşey doğrultuda bir hat halinde sabitlenmesini sağlayan konsol elemanlarıdır. Konsol elemanları deprem dalgalarının meydana getirdiği zorlanmalar nedeniyle hasar görebilir. Bu tip ani zorlanmalar neticesinde karşı ağırlığın ve kabinin ray üzerindeki doğrusal hareketinin bozulması sonucu asansörler kullanılamaz hale gelebilir (Kayaoğlu vd., 2011).

Türkiye dünyada sismik olarak en aktif bölgelerden biridir (Bozkurt, 2001). Dünyanın birçok yerinde olduğu gibi Türkiye de yıllardır farklı zamanlarda şiddetli depremlerle sarsılmaktadır. Son yayınlanan güncel Türkiye Deprem Tehlike Haritası Şekil 1 'de görülmektedir (AFAD, 2018). Depremin asansör sisteminde oluşturduğu hasar; etki süresi, şiddet, deprem merkezine uzaklık, asansörün montaj kalitesi ve elemanları gibi etmenlere bağlı olarak ortaya çıkmaktadır.

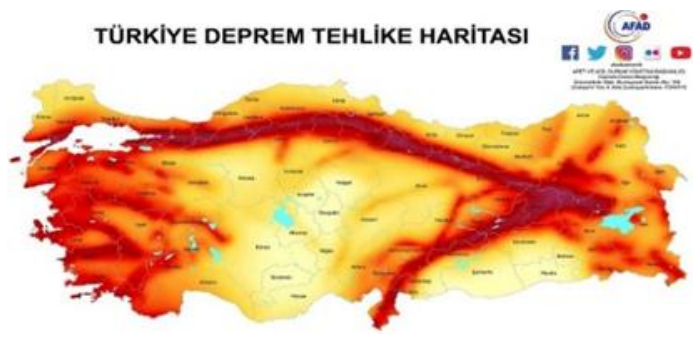

Şekil 1. Türkiye Deprem Tehlike Haritası (AFAD, 2018).
Deprem anında ve sonrasında asansörde mahsur kalınmaması için asansörler kullanılmamaktadır. Bununla beraber, özellikle yüksek binalarda acil durumlarda asansörlerin tahliye maksadıyla kullanılması için yapılan çalışmalar vardır (Andrée vd., 2016; Ding vd., 2021). Wang vd. (2017) beş katlı gerçek ölçekte bir bina modelinde deprem modellemesi yapmışlardır ve konsol elemanlarının farklı yer değiştirmeleri sonucunda raylarda plastik deformasyon meydana gelebileceğini belirtmişlerdir. Karşı ağırlık montajında sismik yükler altında paten ile ray arasındaki montajın matematiksel modellemesi üzerine çalışmalar mevcuttur (Wang vd., 2020; 2021). Mazza ve Labernarda (2021) asansör kuyularının izolasyonu ile asansör sistemi üzerine etkiyen sismik yüklerin azaltılabileceğini gösteren sayısal modellemeler yapmışlardır.

Deprem ve diğer acil durumlarda asansörlerin daha güvenli duruma getirilmesi ile ilgili çalışmalar güncel literatürde yer almaktadır. Tablo 1'de, 2011 Van Depremi'nde asansörlerde meydana gelen hasarların asansör elemanlarına göre dağılımları yer almaktadır (İmrak, 2012). Şekil 2'de 2011 yılındaki Van Depremi'nin ardından yapılan tespit çalışmalarında konsollarda meydana gelen plastik deformasyon ve hasar görülmektedir. Asansörler, asansör kuyusu adı verilen bölüm içerisinde çalışmaktadır. Kabin ve karşı ağırlık kılavuz raylara montaj edilerek düşey yönde hareket ederler. Konsol elemanları kılavuz rayları duvara sabitleyerek rayların düşey doğrultusunu korumasını sağlamaktadır. Van Depremi örneğinde de görüldüğü üzere kılavuz rayların sabitlenmesi oldukça önemlidir. Bu çalışmada, asansör konsol elemanının deprem yükleri altında sonlu elemanlar yöntemi ile analizi yapılmıştır. Bu kapsamda asansörün kılavuz ray ve konsol bağlantısının 3 boyutlu tasarımı yapılmıştır. Ardından ASME A17.1 (ASME, 2016) ve TS EN 81-77 (TSE, 2020a) standartlarında yer alan sismik yüklere ilişkin hesaplama yöntemleri kullanılarak modelleme parametreleri açıklanmıştır. Son olarak, hesaplar sonucunda bulunan deprem yükleri ile standart konsol tasarımı ve destekli konsol tasarımının sonlu elemanlar metodu kullanılarak analizi yapılmış ve modeller karşılaştırılmıştır.

Tablo 1. Sismik yüklere maruz kalan asansörlerin hasarlanan elemanları.

\begin{tabular}{c|l|c}
\hline Deprem & Hasar & Hasar Oranı (\%) \\
\hline & Karşı ağırlı çerçevesinin raylardan çıkması & 52 \\
2011 Van Depremi & Karşı ağırlı çerçeve pabuçlarının kırılması & 17 \\
(Tahrik kasnaklı asansör) & Ray konsollarının kırılması veya hasar görmesi & 14 \\
& Kat kapılarında sorunlar & 13 \\
& Güvenlik tertibatının tetikleme halatının gevşek olması & 4 \\
\hline & Karşı ağırlı çerçevesinin raylardan çıkması & 39 \\
2011 Van Depremi & Halatların konsollara dolanması & 16 \\
(MRL Asansör) & Karşı ağırlı çerçeve pabuçlarının kırılması & 15 \\
& Kat kapılarının sıkışması ve sorunları & 15 \\
& Halatın hasara uğraması veya kasnaktan çıkması & 15 \\
\hline
\end{tabular}
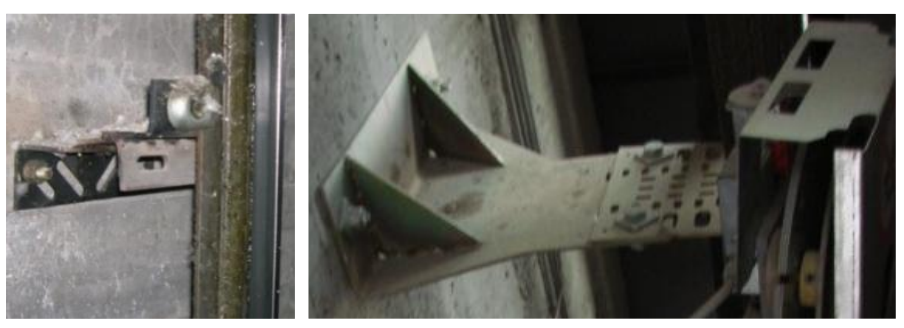

Şekil 2. Konsol eğilmesi, hasara uğraması (İmrak, 2012). 


\section{Materyal ve Metot}

$\mathrm{Bu}$ bölümde kabin kılavuz ray ve konsol elemanlarının tasarım ilkeleri açıklandıktan sonra çalışmada kullanılan parametreler verilmiştir. ASME A17.1 (ASME, 2016) ve TS EN 81-77 (TSE, 2020a) standartlarına göre deprem yükleri hesapları yapılmış ve deprem yükleri karşılaştırılmıştır. Son olarak analizde kullanılan sonlu elemanlar metodunun ilgili değişsen ve parametreleri verilmiştir.

\subsection{Mekanik Elemanlar}

Bu bölümde deprem yüklerinden etkilenen asansör mekanik elemanlarından kabin kılavuz rayı ve kılavuz ray konsolu ele alınmıştır.

\subsubsection{Kulavuz Ray}

Kılavuz raylar kabinin düşey hareketini sağlamak, yatay hareketini sınırlamak ve paraşüt fren tertibatı çalıştığında kabini durdurmak için kullanılan asansör elemanlarıdır (İmrak ve Gerdemeli, 2000). Belirli aralıklarla konsollar vasitasıyla asansör kuyusu duvarına bağlanırlar.

(a)

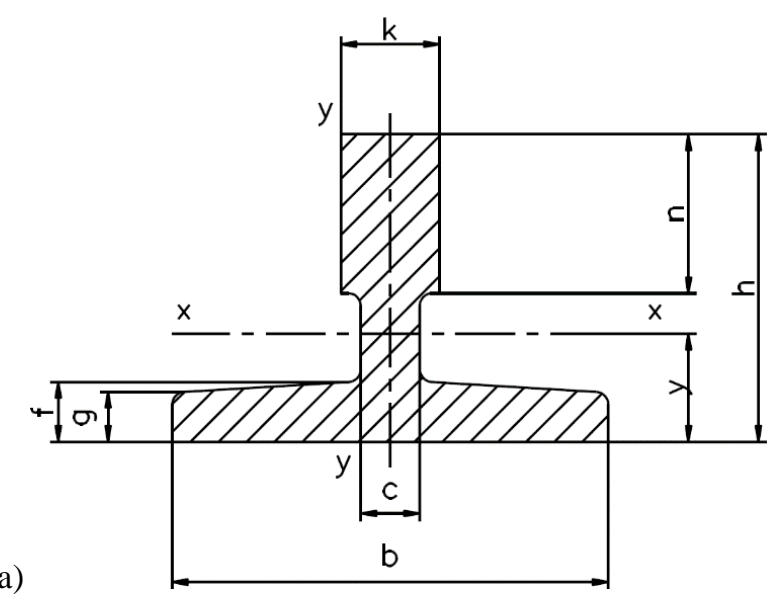

Şekil 3(a)'da bir kılavuz raya ait ölçüler; Şekil 3(b)'de ise standartta yer alan raya etkiyen kuvvetlerin yönleri ve eksen takımı görülmektedir. Bu çalışmada kullanılan T 90/B ray tipinin ölçüleri Tablo 2'de verilmiştir.

Tablo 2. T90/B Ray tipi ölçüleri (mm).

\begin{tabular}{|c|c|c|c|c|c|c|c|c|}
\hline K. Ray & b & h & k & n & c & g & f & y \\
\hline T 90/B & 90,0 & 75,0 & 16,0 & 42,0 & 10,0 & 8,0 & 10,0 & 26,12 \\
\hline
\end{tabular}

\subsubsection{Konsol}

Konsollar kılavuz rayları asansör kuyusunun duvarına sabitler. En az S235JR (St-37) kalitesinde çelik malzemeden imal edilirler ve çekme dayanımı en az $360 \mathrm{MPa}$ olmalıdır (TSE, 2012). Ray kavrama tırnağ 1 konsol ile kılavuz rayı birbirine bağlayan ve kılavuz raya uyumlu olarak rayı iki taraftan tutan çelik bir elemandır. Ray kavrama tırnağının malzemesi en az S355JR (St-52) kalitesinde çelik olmalıdır ve en az $510 \mathrm{MPa}$ çekme dayanımına sahip olmalıdır (TSE, 2012).

Şekil 4'te kılavuz ray-konsol bağlantısının ön ve arka görünüşleri yer almaktadır.

Şekil 3. (a) Asansör kllavuz ray profili (Imrak ve Gerdemeli, 2000), (b) Ray eksenleri ve etkiyen kuvvetler (TSE, 2020b).

(a)

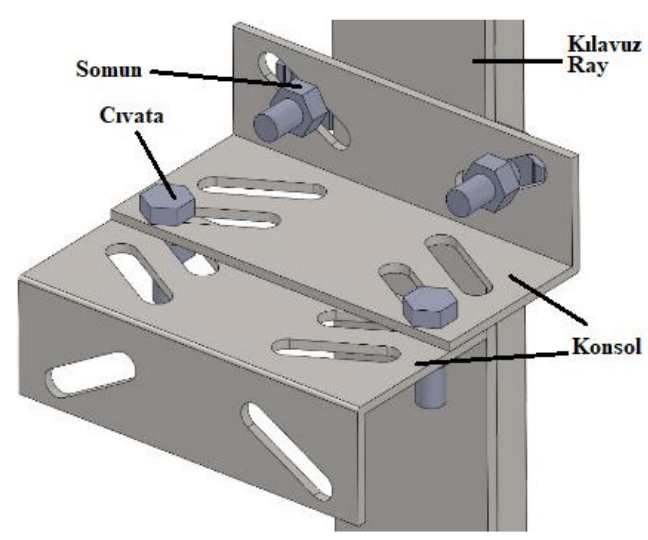

(b)

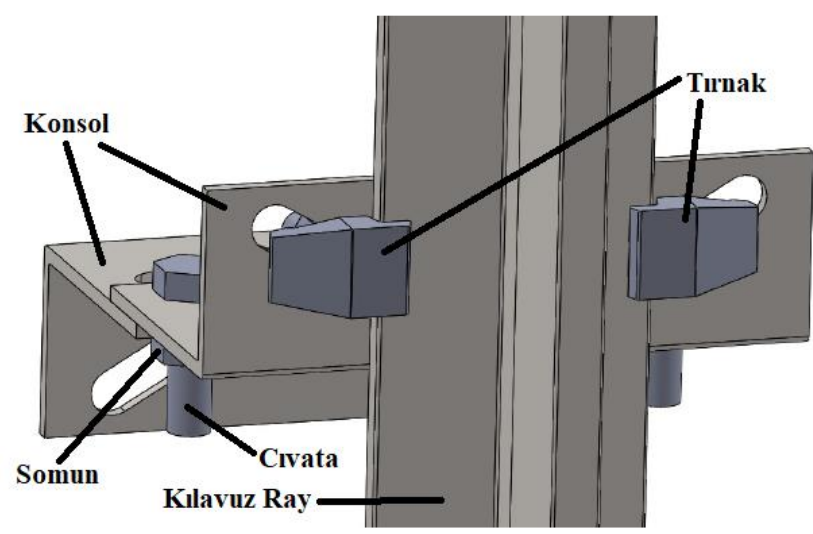

Şekil 4. Kılavuz ray/konsol bağlantısının (a) ön ve (b) arka görünüşü.

\subsection{Tasarım Parametreleri}

Bu çalışmada, Sancak'ın (2020) yüksek lisans tezinde yapılan çalışmalar referans alınarak; tasarımda ve analizlerde kullanılacak parametreler Tablo 3’te verilmiştir. Tabloda görülen normal kullanımda oluşan gerilme kuvvetleri Sancak'ın (2020) tez çalışmasında hesaplanmıştır. 
Tablo 3. Çalışmada kullanılan asansör sistemi tasarım parametreleri.

\begin{tabular}{l|l|l}
\hline Tanım & Sembol & Değer \\
\hline Asansör tipi & & Yolcu asansörü \\
Yolcu kapasitesi & $Q$ & $10 \mathrm{kişi}$ \\
Asansör beyan yükü & $P$ & $800 \mathrm{~kg}$ \\
Asansör boş kabin ağırlığı & $1100 \mathrm{~kg}$ \\
Bina kat sayısı & $n$ & 8 \\
Asansör kuyusu yüksekliği & & $25 \mathrm{~m}$ \\
Kılavuz ray sıra adedi & $h_{p}$ & Simetrik, 2 \\
Bir kılavuz ray sırasında bulunan ray adedi & $C_{w}$ & 5 \\
Kabin kılavuz patenleri arası mesafe & $C_{d}$ & $2200 \mathrm{~mm}$ \\
Asansör kabin boyutları & $C_{h}$ & $1350 \mathrm{~mm}$ \\
Normal kullanımda x-ekseninde oluşan kuvvet & $F_{x}$ & $1400 \mathrm{~mm}$ \\
Normal kullanımda y-ekseninde oluşan kuvvet & $F_{y}$ & $2200 \mathrm{~mm}$ \\
Normal kullanımda düşeyyönde oluşan kuvvet & $F_{v}$ & $566 \mathrm{~N}$ \\
\hline
\end{tabular}

\subsection{TS EN 81-77 Standardına Göre Deprem Yüklerinin Hesabı}

TS EN 81-77 (TSE, 2020a) standardına göre ivme ve deprem kuvvetleri hesaplanmıştır.

$\gamma_{a}=1,5, \quad q_{a}=2, \frac{z}{h}=1, \quad a_{g}=0,772 g, \quad S=1,2$,

$T_{a}=0, \quad T_{1}=0,2 \mathrm{~s}$

$\alpha=\frac{a_{g}}{g_{n}}=\frac{0,772 \times(9,81)}{9,81}=0,772$

$S_{a}=\alpha \times S \times\left(\frac{3 \times\left(1+\frac{z}{h}\right)}{1+\left(1-\frac{T_{a}}{T_{1}}\right)^{2}}-0,5\right)$

$$
\begin{aligned}
& =0,772 \times 1,2 \times\left(\frac{3 \times(1+1)}{1+(1-0)^{2}}-0,5\right) \\
& =2,316
\end{aligned}
$$

$a_{d}=S_{a} \times\left(\frac{\gamma_{a}}{q_{a}}\right) \times g_{n}=2,316 \times\left(\frac{1,5}{2}\right) \times 9,81=17 \frac{\mathrm{m}}{\mathrm{s}^{2}}>4$

Burada; $a_{d}$ tasarım ivmesi, $S_{a}$ yapısal olmayan elemanların sismik katsayısı, $\gamma_{a}$ elemanın önem katsayısı, $q_{a}$ elemanın davranış faktörü, $\alpha$ yer tasarım ivmesinin yer çekimi ivmesine oranı, $a_{g}$ yer tasarım ivmesi, $S$ toprak faktörü, $T_{a}$ yapısal olmayan elemanın temel titreşim periyodu, $T_{l}$ binanın temel titreşim periyodu, $h$ bina boyu, $z$ yapısal olmayan elemanın binada bulunduğu yüksekliktir. $\gamma_{a}, q_{a}, a_{g}, S$ değerleri TS EN 1998-1'den (TSE, 2005) seçilmiştir. Tasarım ivmesi 4'ten büyük hesaplandığ 1 için TS EN 81-77'ye göre Asansör Sismik Kategorisi 3 (Önemli düzeltici eylemler gerekli) olarak tespit edilmiştir. TS EN 81-77'ye göre deprem kuvveti hesaplanmıştır:

$F_{S E}=a_{d} \times(P+0,4 \times Q)=24200 \mathrm{~N}$

Deprem yükünün kütle merkezinden etki ettiği varsayılır. Kütle merkezinin kabin zeminine olan uzaklığının $\left(Z_{S E}\right)$ kabin yüksekliğine $\left(C_{h}\right)$ oranı ile kütle merkezi oranı $\left(X_{S E}\right)$ hesaplanır:

$X_{S E}=\frac{Z_{S E}}{C_{h}}=\frac{640}{2200}=0,291$
Deprem kuvetinin hesapları yapılırken en büyük kuvvet bulunması için $X_{S E}$ veya $\left(1-X_{S E}\right)$ 'den büyük olanı aşağıdaki denklemlerde kullanılır. Eksenlere göre deprem yükü hesaplanır.

$\mathrm{x}$ eksenine etkiyen deprem yükü için $\left(a_{x}=a_{d}, a_{y}=0\right)$ :

$$
\begin{aligned}
F_{S E_{x}} & =\frac{a_{x} \times(P+0,4 \times Q) \times\left(X_{S E} \| 1-X_{S E}\right)}{n} \\
& =\frac{F_{S E} \times\left(1-X_{S E}\right)}{2}=8579 \mathrm{~N}
\end{aligned}
$$

y eksenine etkiyen deprem yükü için $\left(a_{x}=0, a_{y}=a_{d}\right)$ :

$$
\begin{aligned}
F_{S E y} & =\frac{a_{y} \times(P+0,4 \times Q) \times\left(X_{S E} \| 1-X_{S E}\right)}{n / 2} \\
& =\frac{F_{S E} \times\left(1-X_{S E}\right)}{2 / 2}=17158 \mathrm{~N}
\end{aligned}
$$

\subsection{ASME A17.1 Standardına Göre Deprem Yüklerinin Hesabı}

Deprem anında asansöre etki eden yatay kuvvetler ASME A17.1 (ASME, 2016) standardına göre hesaplanır:

$$
F_{p}=\frac{0,4 \times a_{p} \times S_{D S} \times g_{n} \times W_{p}}{\left(\frac{R_{p}}{I_{p}}\right)} \times\left(1+2 \times\left(\frac{Z}{h}\right)\right)
$$

Deprem nedeniyle asansöre etki eden düşey yönlü kuvvet aşağıdaki formülle hesaplanır:

$$
F_{v}= \pm 0,2 \times S_{D S} \times W_{p} \times g
$$

$F_{p}$ kılavuz raya etkiyen depremden kaynaklı yatay kuvvet, $a_{p}$ bileşen büyütme faktörü, $S_{D S}$ kısa periyot tasarım spektral ivme katsayısı, $S_{S}$ kısa periyot harita spektral ivme katsayısı, $F_{a}$ kısa periyot bölgesi için yerel zemin etki katsayısı, $I_{p}$ bileşen önem faktörü, $R_{p}$ bileşen yanıt değişim faktörü, $W_{p}$ boş kabin ağırlığg ile $\% 40$ beyan yükünün toplam değeri, $z$ incelenen bileşenin binada bulunduğu yüksekliği ve $h$ yap1 yüksekliğidir. Kısa periyot tasarım spektral ivme katsayısı değeri $\left(S_{D S}\right)$ :

$$
S_{D S}=F_{a} \times S_{S}
$$


AFAD kurumunun internet sitesinden seçilecek bölge için alınan veriler kullanılarak $F_{a}$ ve $S_{S}$ değerleri tespit edilmiştir (AFAD, 2020). Belirtilen denklemlerle bulunan yatay deprem kuvvetinin k1lavuz rayın $\mathrm{x}-\mathrm{x}$ eksenine ve $\mathrm{y}-\mathrm{y}$ eksenine hangi oranlarda dağılacağını, kabine bağlanan düşeyde alt ve üst sinırları belli olan sinırlamalar $(L)$ ve iki konsol arasındaki mesafe $(l)$ belirler. Burada IBC (2017) standardına atıf yapılan hesaplamalar kullanılmıştır:

Ĕger $L \geq l$;

$F_{x-x}=\frac{2 \times F_{p}}{3}$

$$
F_{y-y}=\frac{F_{p}}{3}
$$

Eğer $L<l$;

$F_{x-x}=F_{p} \times\left(1-\frac{L}{3 \times l}\right) \quad F_{y-y}=\left(\frac{F_{p}}{2}\right) \times\left(1-\frac{L}{3 \times l}\right)$

$F_{y-y}$ değeri y-y eksenine normal kuvvettir ve hesaplamalarda $F_{x}$ değerine eklenmektedir. $F_{x-x}$ değeri x-x eksenine normal kuvvettir ve hesaplamalarda $F_{y}$ değerine eklenmektedir. Türkiye Deprem Tehlike Haritaları İnteraktif Web Uygulaması'ndan (AFAD, 2020) Türkiye haritası üzerinde Bingöl ili yakınlarında yüksek riskli bir bölge için zemin sınıfı ZC, deprem yer hareketi düzeyi DD-2 olarak seçilerek, $F_{a}=1,2$ ve $S_{s}=2,031$ değerleri alınmıştır.

Seçilen ve elde edilen değerler kullanılarak mevcut tasarım için konsola etkiyen yatay $\left(F_{p}\right)$ ve düşey $\left(F_{v}\right)$ kuvvet hesaplanırsa:

$a_{p}=1, \quad R_{p}=2,5, \quad I_{p}=1,5, \quad \frac{z}{h}=1$,

$W_{p}=1100+320=1420 \mathrm{~kg}$

$S_{D S}=1,2 \times 2,031=2,4372$

$F_{p}=\frac{0,4 \times 1 \times 2,4372 \times 9,81 \times 1420}{\left(\frac{2,5}{1,5}\right)} \times(1+2 \times$

$$
=24450 \mathrm{~N}
$$

$F_{v}=0,2 \times 2,4372 \times 1420 \times 9,81=6792 \mathrm{~N}$

bulunur. Konsollar arası düşey mesafe, $l=2500 \mathrm{~mm}$ ve patenler arası düşey mesafe, $L=2200 \mathrm{~mm}$ olduğundan $L<l$ olmaktadır. Böylece, deprem kuvvetleri şu şekilde bulunur:

$F_{x}=F_{y-y}=\left(\frac{24450}{2}\right) \times\left(1-\frac{2200}{3 \times 2500}\right)=8640 \mathrm{~N}$

$F_{y}=F_{x-x}=24450 \times\left(1-\frac{2200}{3 \times 2500}\right)=17279 \mathrm{~N}$

\subsection{Normal Çalışma Yükleri ve Deprem Yüklerinin Bileşkesi}

Bileşke kuvvetleri hesaplanırken TS EN 81-77'ye göre daha büyük kuvvetler bulunan ASME A17.1 standardında elde edilen sonuçlar kullanılmıştır. Buna göre:

$F_{x}=566+8640=9206 \mathrm{~N}$

$F_{y}=1119+17279=18398 N$

$F_{v}=3325+6792=10117 \mathrm{~N}$

olarak bulunur. Kılavuz ray ile konsollar arasına uygulanan yağ nedeniyle kılavuz ray ile konsol arasındaki sürtünme kuvveti katsayısı 0,16 olarak kabul edilmektedir.
Böylece konsola etkiyen düşey kuvvet:

$F_{v_{\text {konsol }}}=F_{y} \times \mu=18398 \times 0,16=2944 \mathrm{~N}$

\subsection{Sonlu Elemanlar Analizi}

Hesaplamaların ardından tasarım parametreleri belirlenen montajın üç boyutlu tasarımları yapılmıştır. Sonlu elemanlar analizi için ANSYS 19.2 programı kullanılmıştır. Şekil 5(a)'da görüleceği üzere konsol elemanları asansör kuyusu zemininden başlayarak kodlanmıştır. 25 metre yüksekliğinde bir bina için 2,5 $\mathrm{m}$ konsol aralığ isimlendirilmiştir. Kılavuz raya etkiyen kuvvetler Şekil 5(b)'de görüleceği üzere sirasılla; $F_{x}, F_{y}, F_{z}$ olarak sisteme uygulanmıştır. Duvar tarafındaki konsollar sabitlenmiş destek olarak kabul edilmiştir. Kılavuz raylar rijit kabul edilmiştir. Her simülasyonda ortalama 960.000 ağ elemanı (mesh) bulunmaktadır. Simülasyon çalışmasında kullanılan eleman tipleri SOLID186, SOLID187, MASS21, TARGE170, SURF154 ve CONTA174'tür. Yuvarlak kenarların daha iyi analiz edilmesi için ANSYS programında bulunan "adaptive mesh" kullanılmıştır. Standart konsol tasarımı ve destekli konsol tasarımı olarak iki farklı model için simülasyonlar yapılmıştır.

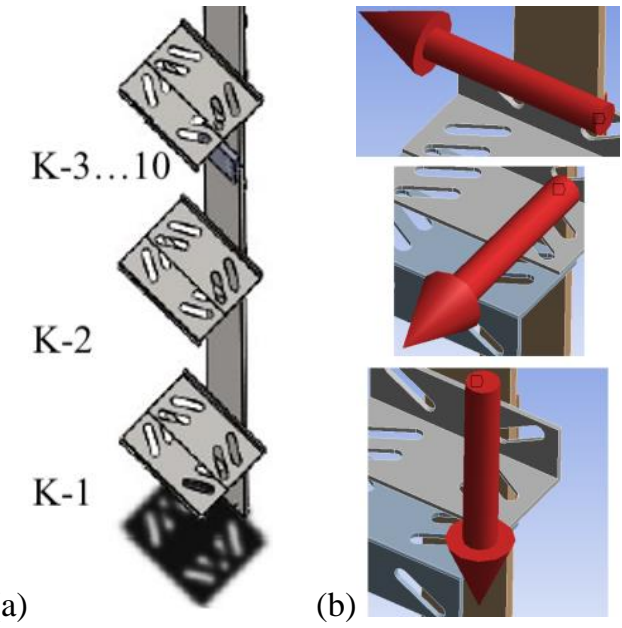

Şekil 5. Kılavuz ray konsol bağlantısı sınır koşulları.

\section{Araştırma Sonuçları ve Tartışma}

En krtitik konumda bulunan kılavuz ray konsol montajının orta bölümünde yer alan K-5 ve K-6 konsolları ele alınmıştır. Konsollar için standart ve destekli olmak üzere iki farklı tasarım geliştirilmiş ve tasarımlar karşılaştırılmıştır.

\subsection{Standart Konsol Tasarımı}

K-5 konsolunun hizasından etkiyen kuvvetler neticesinde en yüksek gerilme değerinin kılavuz ray ile duvara bağlı konsol elemanı arasındaki konsolda, konsolun montajı için kullanılan yuva deliğinde $148 \mathrm{MPa}$ değeriyle oluştuğu görülmüştür (Şekil 6(a)). En büyük deformasyon değeri $0,242 \mathrm{~mm}$ olarak bulunmuştur. K-6 konsolunda elde edilen en yüksek gerilme değeri noktası K-5 ile yaklaşık aynı bölgede $149 \mathrm{MPa}$ olarak tespit edilmiştir (Şekil 6(b)). En büyük deformasyon K-5 konsoluyla aynı olarak 0,242 $\mathrm{mm}$ değerindedir.

\subsection{Destekli Konsol Tasarımı Sonuçları}

K-5 konsolunun incelenmesinde en yüksek gerilme değerinin duvara bağlı konsolda, konsolun montajı için kullanılan yuva deliğinde $109 \mathrm{MPa}$ değerinde meydana geldiği 
görülmüştür (Şekil 7(a)). En yüksek deformasyon değeri 0,091 mm olarak bulunmuştur. K-6 konsolundaki en yüksek gerilme değeri noktası K-5 ile aynı nokta olup, 109 MPa'dır (Şekil 7(b)). Konsolda meydana gelen en büyük deformasyon 0,091 mm'dir.

\subsection{Sonuçların Karşılaştırılması}

Sonlu elemanlar analizleri sonucunda elde edilen sonuçlar değerlendirildiğinde hem standart hem de destekli konsol tasarımlarının analizleri tutarlı sonuçlar vermektedir. Konsolların çekme mukavemeti $360 \mathrm{MPa}$ ve akma mukavemeti, konsol kalınlığı 16 mm altında olduğu için $235 \mathrm{MPa}$ dır. Sonuç olarak elde edilen gerilme ve deformasyon değerleri Tablo 4'te verilmiştir. Standart ve destekli konsollar üzerinde meydana gelen gerilmeler karşılaştırılmıştır. Standart konsol tasarımı için yapılan uygulamalarda destekli tasarıma göre daha yüksek

(a)

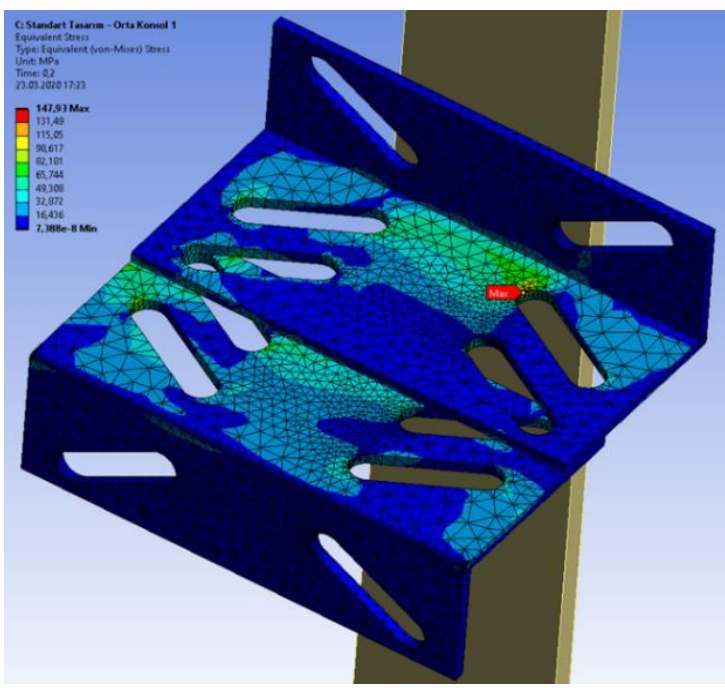

gerilme değerleri bulunmuştur. Seçimi yapılan parametreler için incelenen tasarımların simülasyon sonuçlarında ortaya çıkan gerilme değerlerinin, akma mukavemeti $235 \mathrm{MPa}$ değerinin altında olduğundan, bu çalışma için seçilen tasarım parametreleri ile konsollarda kalıcı bir deformasyon görülmemiştir.

Tablo 4. Standart ve destekli konsol tasarımları gerilme ve deformasyon sonuçları.

\begin{tabular}{l|c|c|c|c}
\hline & \multicolumn{2}{|c|}{$\begin{array}{c}\text { En Büyük } \\
\text { Gerilme, (MPa) }\end{array}$} & \multicolumn{2}{c}{$\begin{array}{c}\text { En Büyük } \\
\text { Deformasyon, } \\
(\mathrm{mm})\end{array}$} \\
\cline { 2 - 5 } Tasarım / Konsol No & $\mathrm{K}-5$ & $\mathrm{~K}-6$ & $\mathrm{~K}-5$ & $\mathrm{~K}-6$ \\
\hline Standart konsol tasarımı & 148 & 149 & 0,242 & 0,242 \\
Destekli konsol tasarımı & 109 & 109 & 0,091 & 0,091 \\
\hline
\end{tabular}

(b)

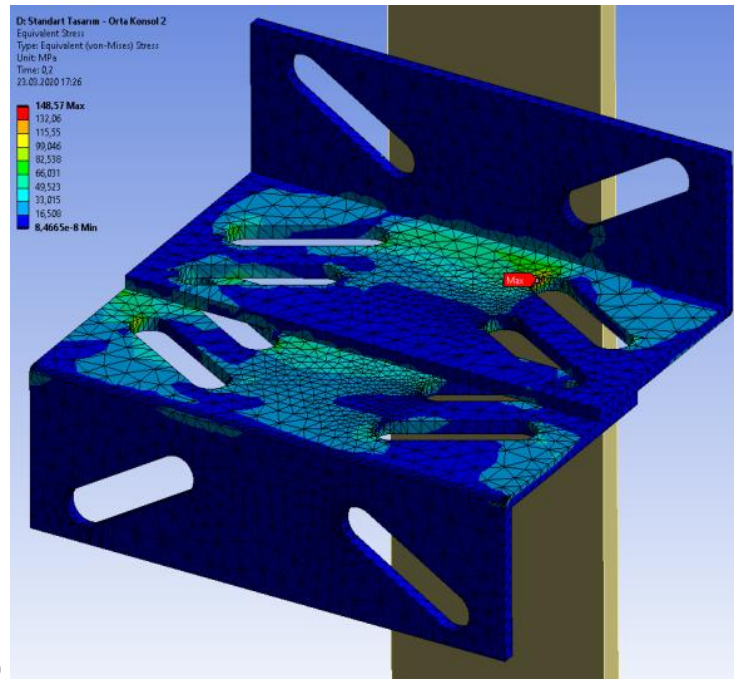

Şekil 6. Standart konsol tasarımlarında meydana gelen gerilmeler: (a) K-5 ve (b) K-6 konsolu.

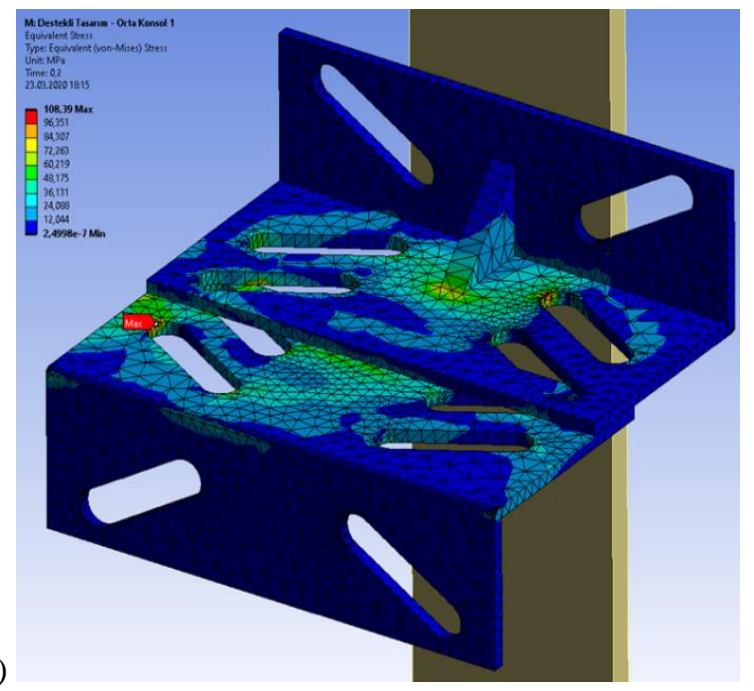

(b)

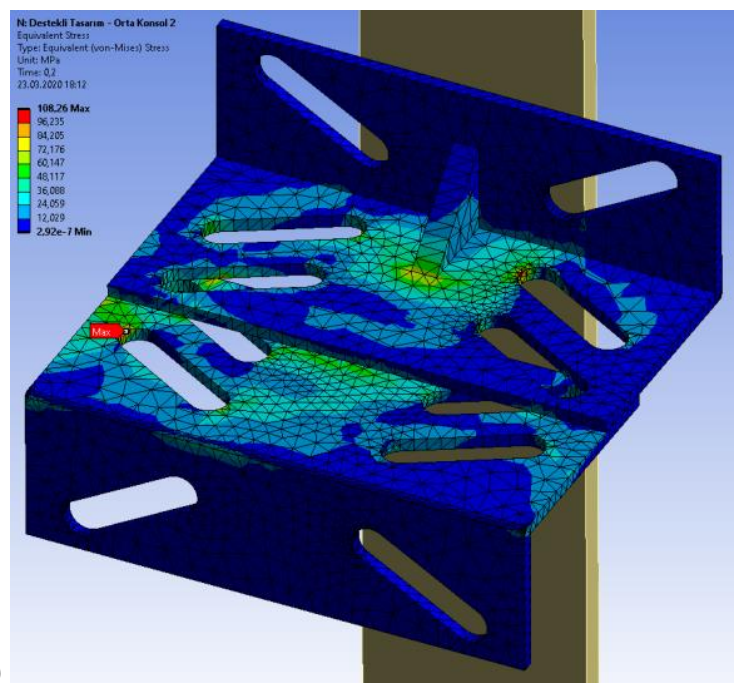

Şekil 7. Destekli konsol tasarımlarında meydana gelen gerilmeler: (a) K-5 ve (b) K-6 konsolu.

\section{Sonuç}

Gerçekte deprem sırasında oluşan kuvvetlerin yönü ve büyüklüğü stokastik olarak değişmekte olduğundan tespiti oldukça zordur. $\mathrm{Bu}$ kuvvetlerin anlık değişmeleri nedeniyle bilgisayar modellerinden elde edilen sonuçlardan daha yüksek gerilmeler meydana gelebilir. Bunun sonucunda ortaya çıkan gerilmeler akma mukavemetini geçebilir. Benzer çalışmalar yapılırken beklenmeyen etkilerin göz önünde bulundurulması gerekmektedir.

İlgili standartlarda yer alan hesaplama yöntemleri ile elde edilen deprem kuvvetleri sonucunda, standart konsol tasarımında oluşan gerilmelerin, destekli konsol tasarımına göre daha büyük olduğu görülmüştür. Bunun nedeni, destek unsurunun konsol 
üzerine etkiyen kuvvetlerin sebep olduğu gerilmeleri azaltması ve gerilmelerin tek bir noktaya etki etmesini önlemesidir. Deformasyon değerleri incelendiğinde de aynı durum görülmektedir.

Çalışma sonucunda konsol tasarımlarının konsol üzerinde meydana gelen gerilmeler üzerinde etkili olduğu görülmüştür. $\mathrm{Bu}$ nedenle, özellikle deprem yükleri nedeniyle oluşan belirsizliklerin sebep olacağı etkiler göz önüne alınırsa, farklı tipteki konsol tasarımları üzerine çalışmalar yapılması faydalı olacaktır. Bir diğer önemli çıkarım, özellikle sismik yüklerin etkili olduğu, deprem riski yüksek bölgelerdeki asansör tesislerinde standart konsol tasarımına göre analizler sonucunda daha düşük gerilme değerleri elde edilen konsol bağlantı eleman tasarımlarının kullanılmasının daha güvenliği olacağıdır.

\section{Kaynakça}

AFAD. (2018). Türkiye Deprem Tehlike Haritası. Erişim: 3 Ekim 2019, url: https://deprem.afad.gov.tr/deprem-tehlikeharitasi

AFAD. (2020). Türkiye Deprem Tehlike Haritaları İnteraktif Web Uygulaması. Erişim: 30 Şubat 2020, url: http://tdth.afad.gov.tr/

Andrée, K., Nilsson, D., \& Eriksson, J. (2016). Evacuation experiments in a virtual reality high-rise building: Exit choice and waiting time for evacuation elevators. Fire and Materials, 40(4), 554-567. https://doi.org/10.1002/fam.2310

ASME. (2016). Handbook on Safety Code for Elevators and Escalators (Standard No. A17.1/CSA B44).

Bozkurt, E. (2001). Neotectonics of Turkey-a synthesis. Geodinamica Acta, 14(1-3), 3-30. https://doi.org/10.1016/S0985-3111(01)01066-X

Ding, N., Chen, T., Zhu, Y., \& Lu, Y. (2021). State-of-the-art high-rise building emergency evacuation behavior. Physica A: Statistical Mechanics and Its Applications, 561. https://doi.org/10.1016/j.physa.2020.125168

IBC. (2017). International Building Code 2018.

İmrak, C. E., Gerdemeli, İ. (2000). Asansörler ve Yürüyen Merdivenler, Birsen Yayınevi, İstanbul.

İmrak, C. E. (2012). A Survey for the Effect of 2011 Van Earthquakes on Elevators. Erişim: https://www.aysad.org.tr/wpcontent/uploads/2018/09/Van_Survey_Appendixes.pdf

Kayaoğlu, E., Salman, Ö., \& Candaş, A. (2011). Study on stress and deformation of an elevator safety gear brake block using experimental and FEA methods. Advanced Materials Research, 308-310, 1513-1518. https://doi.org/10.4028/www.scientific.net/AMR.308310.1513

Mazza, F., \& Labernarda, R. (2021). Internal Pounding between Structural Parts of Seismically Isolated Buildings. Journal of Earthquake Engineering. https://doi.org/10.1080/13632469.2020.1866122

Sancak, A. M. (2020). Asansörlerde kabin kilavuz ray konsollarının sismik bölgeler için tasarımı, modellenmesi ve analizi. Yüksek Lisans Tezi. İstanbul Teknik Üniversitesi, Fen Bilimleri Enstitüsü, İstanbul.

TSE (2005). Eurocode 8: Depreme Dayanıklı Yapı Tasarımı Bölüm 1: Genel Kurallar, Sismik Etkiler ve Binalar için Kurallar (TS EN 1998-1: 2005) (Eurocode 8).

TSE (2012). Asansör Rayı Bağlama Sistemi (Standart No. TSE K 179).
TSE. (2020a). Asansörler - Yapım ve montaj için güvenlik kuralları - Yolcu ve yük asansörleri için özel uygulamalar Bölüm 77: Sismik durumlara tabi asansörler (Standart No. TS EN 81-77:2020).

TSE. (2020b). Asansörlerin Yapımı ve Kurulumu için Güvenlik Kuralları - İnceleme ve Deneyler - Bölüm 50: Asansör Bileşenlerinin Tasarım Kuralları, Hesaplamaları, İncelemeleri ve Deneyleri (TS EN 81-50: 2020).

Wang, X., Hutchinson, T. C., Astroza, R., Conte, J. P., Restrepo, J. I., Hoehler, M. S., \& Ribeiro, W. (2017). Shake table testing of an elevator system in a full-scale five-story building. Earthquake Engineering and Structural Dynamics, 46(3), 391-407. https://doi.org/10.1002/eqe.2793

Wang, X., Günay, S., \& Lu, W. (2020). Seismic analysis of the rail-counterweight system in elevators considering the stiffness of rail brackets. Advances in Structural Engineering. https://doi.org/10.1177/1369433220974777

Wang, X., Günay, S., \& Lu, W. (2021). Mechanical model and seismic study of the roller guide-rail assembly in the counterweight system of elevators. Earthquake Engineering and Structural Dynamics, 50(2), 518-537. https://doi.org/10.1002/eqe.334 